\title{
Maturação tecnológica e qualidade da uva 'Itália' em cultivo protegido sob distintos manejos hídricos
}

\author{
Technological maturity and quality of 'Itália' grape in protected \\ cultivation with different water conditions
}

\author{
Leonardo Cury da Silva ${ }^{\mathrm{I}}$ Henrique Pessoa dos Santos ${ }^{\text {II }}$ Flávio Bello Fialho ${ }^{\text {II }}$ \\ Gilmar Arduino Bettio Marodin ${ }^{\text {III }}$ Homero Bergamaschi'II Carlos Alberto Flores ${ }^{\text {IV }}$
}

RESUMO

Este trabalho teve como objetivos avaliar a maturação tecnológica e as dimensões (diâmetro, comprimento e volume) das bagas de videiras cultivadas em ambiente protegido, submetidas a diferentes condições de disponibilidade hídrica no solo e consumo de água. Utilizaram-se plantas de Vitis vinifera L., cv. 'Itália', enxertadas sobre ' $420 \mathrm{~A}$ ', conduzidas em latada descontínua e cobertas com lonas plásticas de polipropileno trançado impermeabilizado com polietileno $(160 \mu \mathrm{m})$. Os tratamentos constituíram-se de distintos conteúdos de água disponivel no solo, com o tratamento controle (T1) sob condição de capacidade de campo e potencial matricial da água no solo $\left(\psi_{m}\right)$ ao redor de $-33,34 \mathrm{kPa}$. Os demais tratamentos tiveram limites inferiores de $-42,12 \mathrm{kPa}$ (T2), -76,28kPa (T3) e-94,32kPa (T4). Quando esses limites eram alcançados, iniciava-se a irrigação até atingir a capacidade de campo. Os tratamentos T3e T4 anteciparam o ciclo e a maturação tecnológica das bagas em relação ao controle, mas restringiram o acúmulo relativo de sólidos solúveis totais e o volume da baga em relação ao controle. Em contrapartida, $o$ déficit hídrico moderado (T2) apresentou maior eficiência do uso da água pelas plantas, racionalizando o uso da água, e foi a condição mais adequada para incrementar a qualidade das uvas.

Palavras-chave: Vitis vinifera, maturação tecnológica, baga, estresse hídrico.

\section{ABSTRACT}

The present research was conducted to evaluate the technological maturation and the size parameters (diameter, length and volume) of berries subjected to different soil water conditions and water consumption of grapevines, cultivated within a protected environment. The plants were from Vitis vinifera L., 'Itália' cultivar, grafted on '420A', trained on a discontinuous trellis system and total covered with a plastic woven of polypropylene sealed with polyethylene $(160 \mu \mathrm{m})$. Treatments were comprised of specific contents of soil water availability, where the control (T1) was kept under field capacity conditions with a soil water matrix potential $\left(\psi_{\text {o }}\right)$ of $-33.34 \mathrm{kPa}$. The other treatments were represented by $\psi_{m}$ limits of $-42.12 \mathrm{kPa}$ (T2), -76.28 $\mathrm{kPa}(\mathrm{T3})$ and $-94.32 \mathrm{kPa}(\mathrm{T4})$. When the $\psi$ limits were reached the irrigation was performed up to the field capacity condition. The treatments T3 and T4 anticipated the phenological cycle and the technological maturation of berries, but reduced the berry volume and the relative content of total soluble solids, in comparison to the control. In contrast, moderated drought (T2) coupled with greater efficiency of water use by plants and was the best condition to improve the quality of grapes and water saving.

Key words: Vitis vinifera, technological maturation, berry, water stress.

\section{INTRODUÇÃO}

Nos últimos vinte anos, tem ocorrido um crescimento constante na área de vinhedos com cobertura plástica, principalmente em cultivos de uvas de mesa na Região Sul do Brasil, visando à estabilidade de produção, controle sanitário e incrementos de qualidade (CHAVARRIA \& SANTOS, 2012). O emprego dessa nova técnica de cultivo de videiras tem influências diretas sobre as condições microclimáticas e, consequentemente, sobre as respostas das plantas, o que exige ajustes específicos de manejo. Segundo CARDOSO et al. (2008), a cobertura plástica de videiras reduz em

IInstituto Federal do Rio Grande do Sul (IFRS), 95700-000, Bento Gonçalves, RS, Brasil. E-mail: leonardo.cury@bento.ifrs.edu.br. Autor para correspondência.

IIEmbrapa Uva e Vinho, Centro Nacional de Pesquisa de Uva e Vinho, Bento Gonçalves, RS, Brasil.

IIIniversidade Federal do Rio Grande do Sul (UFRGS), Porto Alegre, RS, Brasil.

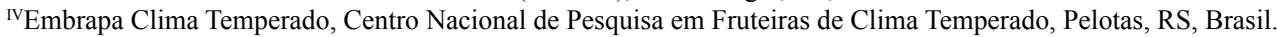


um terço a demanda evaporativa atmosférica. Essa redução é decorrente, sobretudo, da atenuação da velocidade do vento em $90 \%$ e da redução em $33 \%$ da disponibilidade de radiação fotossinteticamente ativa incidente sobre o dossel vegetativo. Como esses dois elementos são considerados os mais importantes na definição da demanda evaporativa atmosférica sob a cobertura, há uma redução na transpiração, favorecendo a condutância estomática e, consequentemente, a assimilação de carbono pelas videiras (CHAVARRIA et al., 2008). Contudo, esse tipo de cobertura também reduz a precipitação na linha de plantio, o que tem impulsionado a instalação de sistemas de irrigação. Apesar destes investimentos, o controle da irrigação tem sido conduzido de modo empírico e sem subsídios técnicos específicos. Em função disso, são frequentes os registros de gastos desnecessários com irrigação, assim como problemas na produção e qualidade dos frutos. De acordo com FERREYRA et al. (2006), a aplicação de déficit hídrico em cultivo convencional (sem cobertura) de 'Crimson Seedless' proporcionou diferenças significativas apenas na produtividade, sobretudo a partir do segundo ciclo de cultivo. $\mathrm{O}$ excesso hídrico pode gerar um crescimento vegetativo demasiado e apresenta-se como um fator de diluição dos sólidos solúveis totais, podendo proporcionar o rompimento das bagas (KELLER et al., 2006). Segundo SOUZA et al. (2013), o estresse hídrico moderado em cultivo convencional de 'Superior Seedless', abaixo da capacidade de campo para solos arenosos $(-30 \mathrm{kPa})$, reduziu em $68 \%$ a lâmina de irrigação em comparação ao controle mantido em capacidade de campo $(-15 \mathrm{kPa})$, além de beneficiar o manejo do dossel vegetativo, pois restringiu o crescimento vegetativo sem alterar o número de cachos por planta.

Segundo KENNEDY (2002), os impactos dos estresses hídricos são mais drásticos quando aplicados no início do desenvolvimento do fruto, durante os primeiros estádios de crescimento da baga (fase I), segundo acurva característica de crescimento, em comparação às fases II (fase lag) e III (WILLIAMS \&TROUT, 2005). Essas informações podem ser distintas para uvas de mesa, nas quais são priorizados aspectos visuais, como uniformidade de maturação e tamanho (PADILLA, 2007), assim como nas condições de cultivo protegido, cujas variações microclimáticas favorecem a eficiência no uso da água (CHAVARRIA et al., 2008). Nessas condições, as videiras podem reduzir as necessidades hídricas ao longo do ciclo para manter ou melhorar, a qualidade das bagas produzidas, em comparação ao cultivo convencional. Apesar dessas evidências, até o presente momento não se dispõe de uma caracterização do comportamento da videira coberta em relação às variações na lâmina de irrigação. Com esta indisponibilidade de parâmetros técnicos para o manejo hídrico adequado em cultivo protegido, observa-se o uso excessivo de irrigação neste sistema, gerando impactos diretos sobre os custos de produção e sobre o ambiente, devido ao consumo desnecessário de água e lixiviação de nutrientes. Diante disso, constata-se a importância da avaliação dos efeitos do déficit hídrico sobre as características qualitativas da uva em cultivo protegido, com o propósito de gerar referências técnicas para o desenvolvimento de um manejo hídrico efetivo e sustentável para este novo sistema de cultivo da videira.

\section{MATERIAL E MÉTODOS}

O experimento foi realizado nos ciclos 2009/10 e 2010/11, em um vinhedo comercial no Vale dos Vinhedos, Bento Gonçalves (latitude $29^{\circ} 12^{\prime} \mathrm{S}$, longitude $51^{\circ} 32^{\prime} \mathrm{W}$ e altitude aproximada de $660 \mathrm{~m}$ ). Foram utilizadas plantas de Vitis vinifera L., cv. 'Itália', com seis anos de idade, enxertadas sobre o porta-enxerto ' $420 \mathrm{~A}$ ' e espaçadas a 3,0m entre filas e $1,8 \mathrm{~m}$ entre plantas. As filas estavam dispostas na direção norte-sul, conduzidas em sistema latada descontínua, com poda mista, quatro varas (cinco gemas) e 12 esporões (duas gemas) por planta (93 mil gemas ha-1). Para a cobertura, foram utilizadas lonas plásticas de polipropileno (PP) trançado transparente, impermeabilizadas com polietileno de baixa densidade $(160 \mu \mathrm{m})$. Para evitar que a entrada de água no solo via precipitação atingisse a área experimental, foram instaladas calhas com a mesma lona (PP) nas entrelinhas de cada bloco experimental, assim como nas oito linhas acima destes.

O solo da área foi classificado como argissolo bruno acinzentado alítico abrúptico, com horizonte A moderado de textura média/argilosa e drenagem moderada. Os horizontes foram caracterizados segundo sua morfologia e subdivididos de acordo com a profundidade. Da superfície até $10 \mathrm{~cm}$, o horizonte foi classificado como A proeminente (Ap), entre 10 e $40 \mathrm{~cm}$ como transição BA e entre $40 \mathrm{e}$ $75 \mathrm{~cm}$ como B textural $(\mathrm{Bt})$, contemplando, em todos estes horizontes, $90 \%$ do sistema radical das videiras. Em cada horizonte, foram coletadas três amostras indeformadas de solo, utilizando-se cilindros de $5 \mathrm{~cm}$ de diâmetro e $2,5 \mathrm{~cm}$ de altura. As amostras foram saturadas com água destilada e submetidas às tensões de $0 \mathrm{kPa}$, solo saturado, e $-1500 \mathrm{kPa}$, referente ao ponto de murcha permanente (PMP), utilizando-se 
uma câmara de Richards (KLUTE, 1986). Segundo RUIZ et al. (2003), o potencial matricial da água em solos sob capacidade de campo (CC) de $-33 \mathrm{kPa}$ é representativo dos solos com maior proporção de argilas. Segundo FLORES et al. (2012), os argissolos representam $28,65 \%$ da área total, distribuídos em 55 unidades de mapeamento de solo do Vale dos Vinhedos abrangendo uma área de 2.327,22ha. Os dados de potencial matricial e sua respectiva umidade volumétrica do solo foram submetidos à análise de regressão não linear,utilizando o programa $R(R$, 2011). De acordo com as curvas ajustadas de retenção de água, os potenciais equivalentes à $\mathrm{CC}$ e ao PMP corresponderam, respectivamente, às umidades volumétricas de 0,277 e $0,234 \mathrm{~cm}^{3} \mathrm{~cm}^{-3}$ no perfil Ap+BA, e 0,345 e $0,318 \mathrm{~cm}^{3} \mathrm{~cm}^{-3}$ no $\mathrm{Bt}$. Com os valores de umidade volumétrica em $\mathrm{CC}\left(\theta_{c c}\right)$ e PMP $\left(\theta_{p m p}\right)$ e profundidade $(Z)$, calculou-se a capacidade de água disponível (CAD $(\mathrm{mm})$ :

$$
\mathrm{CAD}=(\theta \mathrm{cc}-\theta \mathrm{pmp}) \cdot \mathrm{Z}
$$

Os tratamentos e a frequência de irrigação foram determinados segundo a capacidade de água disponível (CAD) nos horizontes Ap+BA (17,2mm) e $\mathrm{Bt}(9,45 \mathrm{~mm})$. O tratamento controle (T1) foi definido mantendo a umidade dos horizontes próxima à $\mathrm{CC}$ $\left[\psi_{\mathrm{m}}=-33,34 \mathrm{kPa}, 27,7 \%\right.$ de umidade em Ap+BA e $34,5 \%$ em Bt $(100 \%$ de $\mathrm{CAD})]$. O conteúdo de água no solo foi monitorado por sondas TDR (Time Domain Reflectometry), marca Campbell ${ }^{\circledR}$, modelo WCR CS616. Após a calibração, os sensores foram instalados em trincheiras distantes em $50 \mathrm{~cm}$ das plantas,no sentido da entrelinha de plantio, medindo a umidade do solo nos horizontes Ap+BA e Bt, a $30 \mathrm{~cm}$ e $50 \mathrm{~cm}$ de profundidade, respectivamente. As doses de rega e frequência de irrigação foram aplicadas de modo a estabelecer diferentes níveis de restrição hídrica às videiras, de acordo com o consumo de água da cultura (evapotranspiração). O limite mínimo da umidade volumétrica em T2 foi definido em $27 \%$ no horizonte Ap+BA e 34,2\% no Bt, com CAD reduzida a $83 \%\left(\psi_{\mathrm{m}}=-42,12 \mathrm{kPa}\right)$. Em T3, a CAD foi reduzida para $53 \%$, com umidades mínimas de $25 \%$ no Ap+BA e $33,4 \%$ no horizonte $\mathrm{Bt}\left(\psi_{\mathrm{m}}=\right.$ $-76,28 \mathrm{KPa})$. A CAD em T4 foi reduzida para $30 \%$, mantendo como limites mínimos 24,4\%em Ap+BA e $32,8 \%$ em Bt $\left(\psi_{\mathrm{m}}=-94,32 \mathrm{KPa}\right)$. Quando o limite mínimo da umidade volumétrica era atingido em cada horizonte (Ap+BA e Bt), iniciava-se a irrigação, com tempos e volumes pré-calculados para atingir a $\mathrm{CC}$ em cada um dos horizontes. Considerando que o horizonte Bt apresentava uma quantidade elevada de argila e levava mais tempo para atingir os limites considerados, este horizonte manteve a umidade do solo por mais tempo. No início do ciclo, a irrigação foi baseada na umidade volumétrica do horizonte $\mathrm{Ap}+\mathrm{BA}$, entretanto, quando a água disponível no horizonte Bt alcançava o limite pré-determinado, a lâmina de irrigação passava a ser calculada com base na umidade volumétrica deste horizonte. Para a aplicação da lâmina de irrigação, foram utilizados microaspersores auto-compensados de $30 \mathrm{~L} \mathrm{~h}^{-1}$ de vazão, com raio efetivo de $1,8 \mathrm{~m}$, a uma razão de 0,6 aspersores por planta e com $40 \%$ de sobreposição. $\mathrm{O}$ cálculo do tempo de irrigação, para cada tratamento, foi calculado com base na metodologia proposta por CONCEIÇÃO (2005), considerando a quantidade de água disponível em cada horizonte, a profundidade (z) de cada horizonte, a vazão e o raio efetivo do aspersor e a eficiência de aplicação por aspersão.

O delineamento experimental utilizado foi composto de quatro blocos casualizados, respeitando a declividade do terreno (5\%), sendo cada parcela composta de oito plantas. Para as análises de maturação, foram coletadas 50 bagas, aleatoriamente, nas duas plantas centrais da parcela em cada bloco, as quais corresponderam à unidade experimental da parcela. A partir de cada amostra, utilizou-se uma subamostra de 20 bagas para as avaliações físicas de comprimento longitudinal $(L)$ e transversal $(d)$, com paquímetro digital para o cálculo do volume da baga $\left(V, \mathrm{~cm}^{3}\right)$, com a seguinte fórmula:

$$
V=\frac{\left(\frac{4}{3}\right) \cdot \pi \cdot d^{2} \cdot L}{8000}
$$

Logo após as medidas físicas, todas as 50 bagas de cada amostra foram reagrupadas e esmagadas para a extração do mosto, o qual foi centrifugado a $3000 \mathrm{rpm}(2000 \mathrm{~g})$, a $20^{\circ} \mathrm{C}$ por 5 minutos. Para as curvas de maturação tecnológica, foi determinado o teor de sólidos solúveis totais $\left(S S T,{ }^{\circ} \mathrm{Brix}\right)$, através de refratômetro digital, modelo PR-101. A acidez total titulável com base em ácido tartárico ( $A T T$, meq $\left.\mathrm{L}^{-1}\right)$ foi medida por titulação do mosto com $\mathrm{NaOH} 0,1 \mathrm{~N}$, com bureta digital, utilizando como indicador $2,5 \mathrm{ml}$ de azul de bromotimol. A razão SST:ATT foi calculada segundo a fórmula:

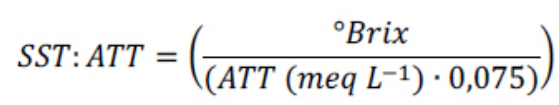

A partir do monitoramento da razão SST:ATT, definiu-se a data de colheita, quando T1 alcançou a razão SST:ATT de 25:1. Para a análise estatística, utilizou-se o programa R (2011). Os dados foram submetidos a análises de variância 
(ANOVA) e de regressões lineares, sendo as médias comparadas pelo teste de Tukey $(\mathrm{P} \leq 0,05)$. Nas análises de regressões lineares de cada variável, as curvas de estimadas dos tratamentos foram comparadas entre si utilizando o teste F, de forma a agrupá-las por grau de semelhança.

\section{RESULTADOS E DISCUSSÃO}

A estratégia de utilização de calhas nas entrelinhas para evitar o ingresso de água via precipitação pluviométrica na área experimental foi eficaz. Ao longo dos ciclos experimentais 2009/10 e 2010/11, foram registrados $1842,8 \mathrm{~mm}$ e $1143 \mathrm{~mm}$ de precipitação, respectivamente. Este volume de água externo não promoveu variações na CAD além das pré-estabelecidas para os respectivos tratamentos de irrigação. As evoluções de SST observadas nos ciclos 2009/10 e 2010/11 podem ser visualizadas nas figuras1A e $1 \mathrm{~B}$, sendo a variação estimada por uma função quadrática. Observa-se que, em ambos os ciclos, as curvas mais semelhantes foram obtidas por T1 e T2 (100\% e 83\% CAD), não diferindo significativamente entre si $(\mathrm{P}=0,61$ e $\mathrm{P}=0,74)$. A segunda maior semelhança ocorreu entre T3 e T4 (53\% e 30\% CAD), que não diferiram no ciclo $2010 / 11(\mathrm{P}=0,93)$, mas foram diferentes $(\mathrm{P}=0,0006)$ no ciclo 2009/10. O contraste mais marcante ocorreu entre (T1 e T2)x(T3 e T4), sendo esta diferença fortemente significativa em ambos os ciclos $(\mathrm{P}<0,0001)$. Essa análise ampla dos dados demonstra que T3 e, principalmente, T4 promovem uma evolução na concentração de SST totalmente distinta do tratamento controle. Aos 29 dias após o início da maturação (DAIM) no ciclo 2009/10 e 28 DAIM em 2010/11, as bagas dos tratamentos mantidos com $53 \%$ e $30 \%$ CAD já haviam alcançado a maturação fisiológica, com uma razão SST:ATT acima de 20:1 (Figuras 1E e 1F). Na colheita, em ambos os ciclos, o nível máximo de SST ocorreu em T4 $\left(18,5^{\circ}\right.$ Brix em $2009 / 10$ e $18,9^{\circ}$ Brix em 2010/11) (Figuras $1 \mathrm{~A}$ e 1B). Em 2009/10, houve diferença de $3,3^{\circ}$ Brix $(\mathrm{P}=0,018)$ entre os tratamentos extremos de T4 e T1. Em2010/11, houve diferença significativa entre T3 e T4 em relação a $\mathrm{T} 1 \mathrm{de} 2,1^{\circ} \mathrm{Brix}(\mathrm{P}<0,0001)$ e $3,1^{\circ}$ Brix $(\mathrm{P}<0,0001)$, respectivamente. Contudo, $\mathrm{T} 1$ e $\mathrm{T} 2$ não diferiram significativamente, salientando que, para essa cultivar e condições experimentais, restrições hídricas de até $83 \%$ CAD não alteram o acúmulo de açúcar na baga. Estes dados não corroboram os encontrados por MARINHO et al. (2009), que relatam diferenças na concentração de SST ao alterar a lâmina de irrigação de $0 \%, 50 \%$ e $100 \%$ de ETc após a virada de cor na cultivar 'Superior Seedless' em cultivo convencional. A evolução na degradação dos ácidos orgânicos nos ciclos 2009/10 e 2010/11 pode ser visualizada nas figuras $1 \mathrm{C}$ e $1 \mathrm{D}$ por uma função quadrática. Contrastando as curvas de catabolização dos ácidos orgânicos, observa-se que, em ambos os ciclos formaram-se dois grupos (T1 e T2 x T3 e T4), os quais foram significativamente distintos em 2009/10 ( $\mathrm{P}=0,0098)$ e 2010/11 $(\mathrm{P}<0,0017)$. Portanto, assim como foi observado para SST, os tratamentos T3 e T4 também proporcionam uma evolução distinta na degradação de ácidos orgânicos em relação ao tratamento controle. Aos 29 DAIM no ciclo 2009/10 e 28 DAIM em 2010/11, os valores de ATT no tratamento de maior deficiência hídrica do solo foi de 78,2 e 65,9 meq L ${ }^{-1}$, respectivamente (Figuras $1 \mathrm{C}$ e 1D), que representam reduções de $34,9 \mathrm{meq}$ $\mathrm{L}^{-1}(\mathrm{P}=0,03)$ e $34,3 \mathrm{meq} \mathrm{L}^{-1}(\mathrm{P}=0,04)$ em relação à T1. Em ambos os ciclos, a menor concentração de ácidos orgânicos foi determinada em T4 (57,3 meq $\mathrm{L}^{-1}$ no ciclo 2009/10 e 53,7 meq L $\mathrm{L}^{-1}$ em 2010/11) e sem diferença significativa em relação à $\mathrm{T} 3$. Com estes valores obtidos em T4, observam-se diferenças de 23,1 meq $\mathrm{L}^{-1}(\mathrm{P}<0,0001)$ em relação a T2 em 2009/10 e 22,1 meq $\mathrm{L}^{-1}(\mathrm{P}<0,0001)$, em relação a $\mathrm{T} 1 \mathrm{em}$ 2010/11. MARINHO et al. (2009) verificaram efeitos semelhantes em plantas mantidas sob ausência de irrigação, após a virada de cor ( $0 \%$ de ETc) na cultivar 'Superior Seedless', o que pode ser não desejável no aspecto qualitativo de uvas de mesa, por reduzir de forma acentuada a razão SST:ATT. Nas figuras 1E e $1 \mathrm{~F}$, que representam a evolução da razão SST:ATT durante os ciclos 2009/10 e 2010/11, percebese que esta razão pode ser estimada por uma função linear. Observa-se que plantas mantidas em 53\% CAD (T3) e, principalmente, em 30\% CAD (T4) proporcionaram uma evolução distinta nesta razão, em comparação aos tratamentos com menor restrição hídrica, o que enfatiza um efeito dos tratamentos de disponibilidade hídrica sobre o metabolismo de açúcares e de ácidos orgânicos. De acordo com BLEINROTH (1993), quando a uva fina de mesa atinge a razão mínima de 20:1 (SST:ATT), apresenta-se em ponto de colheita para comercialização. Durante a evolução da maturação, em ambos os ciclos, os tratamentos de maior restrição hídrica (T3 e T4) apresentaram alta razão SST:ATT, alcançando esse valor médio de 20:1 aos 27 e 15 DAIM em T3, respectivamente, nos ciclos 2009/10 e 2010/11 e aos 22 e 13 DAIM em T4 nos ciclos 2009/10 e 2010/11 ( $\mathrm{P}<0,0001)$ (Figura 1E e 1F). Em 2009/10, os cachos das plantas em T3 e T4 estavam prontos para a colheita, com 

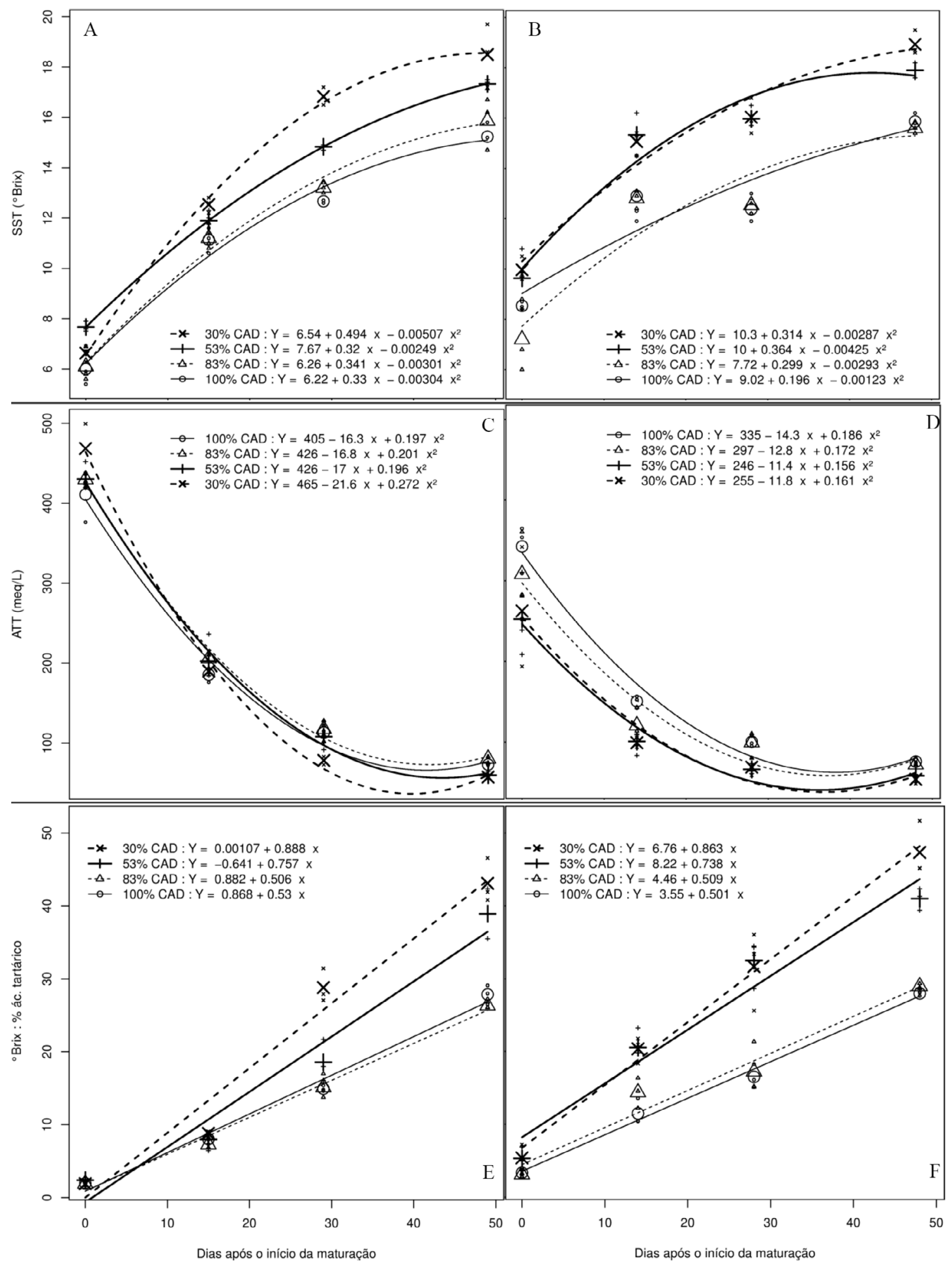

Figura 1 - Evolução dos parâmetros de maturação tecnológica, representados pela concentração de sólidos solúveis totais ( ${ }^{\circ}$ Brix $)$ nos ciclos 2009/10 (A) e 2010/11 (B), pela acidez total tituláves (ATT) (meq L-1) nos ciclos 2009/10 (C) e 2010/11 (D) e pela razão entre sólidos solúveis totais ( ${ }^{\circ}$ Brix) e acidez total titulável (\% de ácido tartárico) nos ciclos $2009 / 10$ (E) e 2010/11 (F),durante a maturação de videiras 'Itália', em ambiente coberto, sob diferentes níveis de restrição hídrica (percentagem da capacidade de armazenagem de água disponível no solo - CAD). Bento Gonçalves, RS, 2011. 
antecipação de 9 e 14, respectivamente, em relação ao T1. Em 2010/11, isto foi mais evidente com os cachos das plantas em T3 e T4 aptos à colheita, com antecipação de 16 e 29 dias, respectivamente, em relação ao T1. Portanto, sob cultivo protegido e restrições hídricas de $53 \%$ e $30 \%$ $\mathrm{CAD}$, ocorreram antecipações médias de colheita de $13 \mathrm{e}$ 22 dias, respectivamente, em relação ao controle.

Para caracterizar os efeitos da restrição hídrica sobre a fisiologia do crescimento, realizouse a determinação do volume de bagas. Em T3 e $\mathrm{T} 4$, o volume das bagas na virada de cor (EF85) já apresentava diferenças significativas $(\mathrm{P}<0,0001)$ em relação ao controle, com reduções de $1,96 \mathrm{~cm}^{3}$ e 2,89 $\mathrm{cm}^{3}$ em $2009 / 10$ e de $1,31 \mathrm{~cm}^{3}$ e $1,39 \mathrm{~cm}^{3}$ em $2010 / 11$ (Figuras 2A e 2B). Segundo ÁVILA NETTO et al. (2000), é no início do crescimento das bagas que a restrição hídrica é mais impactante sobre o volume delas. Na colheita, em 2009/10, o ponto máximo do volume ocorreu em T1, alcançando $10,31 \mathrm{~cm}^{3}$,não diferindo de T2. Em contrapartida, plantas mantidas sob restrição hídrica mais drástica (T3 e T4) apresentaram o menor ganho em volume, alcançando $7,58 \mathrm{~cm}^{3}$ e $6,26 \mathrm{~cm}^{3}$, respectivamente, $(\mathrm{P}<0,0001)$. Em 2010/11, o volume máximo das bagas também foi obtido em T1, aos 35 DAIM, alcançando 10,33 $\mathrm{cm}^{3}$. Contudo, neste último ciclo, o volume das bagas em T1 foi reduzido na colheita, alcançando $9,45 \mathrm{~cm}^{3}$, sem diferir estatisticamente de T2. Esta redução também foi observada em $\mathrm{T} 3$, com redução de $0,59 \mathrm{~cm}^{3}$, e não diferindo estatisticamente de T4. Com o intuito de expor a intensidade relativa do efeito da restrição hídrica sobre a bioquímica da maturação e sobre o crescimento da baga, determinou-se o produto entre SST e o volume individual médio de cada baga. Com essa variável, salienta-se que a maior grandeza de variação, observada ao longo do período de maturação, ocorreu no volume da baga e não em SST, considerando a clara inversão na posição dos tratamentos em comparação à resposta isolada de SST (Compare Figuras 1A, 1B x 2C, 2D). Ou seja, os tratamentos, antes superiores em SST (T3 e T4), apresentaram-se inferiores no produto SSTxVolume e ambos os tratamentos não diferem entre si nos dados $2009 / 10 \quad(\mathrm{P}=0,11)$ e 2010/11 $(\mathrm{P}=0,23)$. Com este resultado e considerando-se que a glicose e a frutose (hexoses) constituem a maior parte na uva (12\% a $27 \%$ da massa fresca) e $99 \%$ dos sólidos solúveis totais na maturação de colheita (RUFFNER et al., 1990), podese afirmar que os limites hídricos impostos por T3 e T4 também comprometeram a função biológica foliar. Em contrapartida, os tratamentos mantidos a $100 \%$ e $83 \% \mathrm{CAD}$, que também apresentaram os maiores volumes de baga, manifestaram os maiores acúmulos totais de açúcares por baga, possivelmente associados aos maiores níveis de síntese foliar, transporte e acúmulo de carboidratos nessas condições hídricas. No aspecto de produção de frutos, destaca-se que os tratamentos com umidade do solo mantida em $100 \%$ e $83 \%$ de CAD proporcionaram valores respectivos de 34,09 e 31,68 $\mathrm{Mg} \mathrm{ha}^{-1}$ no ciclo 2009/2010 e 35,77 e 34,62 $\mathrm{Mg} \mathrm{ha}^{-1} \mathrm{em} \mathrm{2010/11}$, não diferindo estatisticamente entre si. Em média, o rendimento dos tratamentos mais restritivos em água (T2 e T3) foi reduzido em 16,07 e 35,64\% em relação a $\mathrm{T} 1$, com valores respectivos de 28,61 e 21,94 $\mathrm{Mg} \mathrm{ha}^{-1}$ no ciclo 2009/10. No ciclo 2010/11, os tratamentos T2 e T3 foram ainda mais restritivos, atingindo reduções de $35,67 \%$ e 59,37\% em relação ao controle, alcançando 23,01 e 14,53 $\mathrm{Mg} \mathrm{ha}^{-1}$, respectivamente.

De modo geral, o cultivo protegido de videiras associado ao controle do estresse hídrico pode possibilitar melhor qualidade de produção com economia no volume de irrigação. Contudo, é importante que o viticultor efetue o monitoramento do conteúdo de água disponível no solo para não comprometer a vida útil da planta e a qualidade dos frutos, pela restrição da função biológica foliar sobestresses severos, ou prejuízos com volumes de irrigação acima do necessário. Com a redução na taxa transpiratória imposta pela cobertura plástica, o potencial matricial de $-42,12 \mathrm{kPa}$ não foi prejudicial às plantas, agregando qualidade sem alterar as funções biológicas foliares e a produtividade, favorecendo a economia de água e a sustentabilidade econômica e ambiental do vinhedo.

\section{CONCLUSÃO}

Nas condições microclimáticas do cultivo protegido desse trabalho, foi possível atingir uma redução de $17 \%$ do conteúdo de água disponível (CAD) no solo, sem haver comprometimentos na produção e na qualidade da uva de mesa 'Itália'. Restrições mais drásticas, como 53 e 30\% CAD, comprometeram a produção, o tamanho de bagas e o acúmulo de carboidratos totais por baga, apesar da elevação de sólidos solúveis totais pela redução do conteúdo absoluto de água nos tecidos das bagas. Além disso, nesses tratamentos severos de restrição hídrica, houve drástica redução na acidez total e no tempo de evolução do ciclo vegetativo/produtivo. Portanto, pelo aumento da eficiência do uso da água, o cultivo protegido pode ser manejado com déficit hídrico moderado, sem comprometer o aspecto visual das uvas (tamanho de bagas), a maturação e agregar benefícios econômicos e ambientais, com economia de água para produção de uvas finas de mesa. 


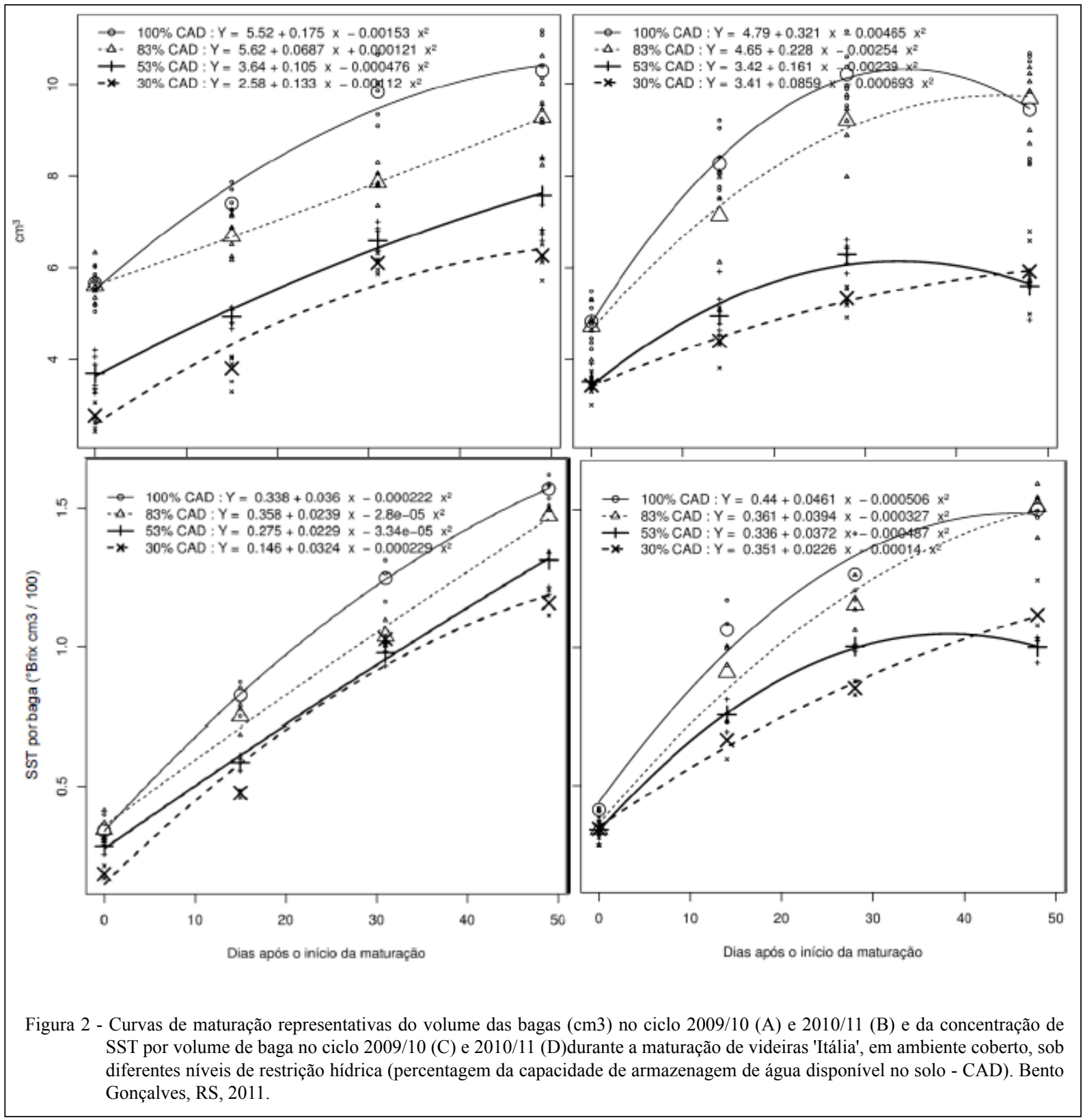

\section{REFERÊNCIAS}

ÁVILA NETTO, J. et al. Exigência hídrica da videira na região do submédio São Francisco. Pesquisa Agropecuária Brasileira, Brasília, v.35, n.8, p.1559-1566, 2000. Disponível em: <http:// www.scielo.br/pdf/pab/v35n8/v35n8a08.pdf> Acesso em: 01 de jun. 2010. Doi 10.1590/S0100-204X2000000800008.

BLEINROTH, E.W. Determinação do ponto de colheita. In: GORGATTI NETO, A. et al. Uva para exportação: procedimentos de colheita e pós-colheita. Brasília: EMBRAPA-SPI/FRUPEX, 1993. p.20-21. (Publicações Técnicas, 2).

CARDOSO, L.S. et al. Alterações micrometeorológicas em vinhedos pelo uso de coberturas de plástico. Pesquisa Agropecuária
Brasileira, Brasília, v.43, n.4, p.441-447, 2008. Disponível em: $<$ http://www.scielo.br/pdf/pab/v43n4/a01v43n4.pdf $>$. Acesso em: 10 de jan. 2010. Doi 10.1590/S0100-204X2008000400001.

CHAVARRIA, G.; SANTOS, H.P. (2012). Plant water relations: absorption, transport and control mechanisms. in advances in selected plant phsyiology aspects. MONTANARO, G.; DICHIO,B. (Eds.). Disponível em: $<$ http://cdn.intechopen.com/ pdfs-wm/35825.pdf > . Acesso em: 27 out 2010.

CHAVARRIA, G. et al. Relações hídricas e trocas gasosas em vinhedo sob cobertura plástica. Revista Brasileira de Fruticultura, Jaboticabal, v.30, n.4, p.1022-1029, 2008. Disponível em: $<$ http:// www.scielo.br/pdf/rbf/v30n4/a30v30n4.pdf $>$. Acesso em: $12 \mathrm{de}$ mar. 2010. Doi 10.1590/S0100-29452008000400030. 
CONCEIÇÃO, M.A.F. Sistema de produção de uva de mesa do Norte de Minas Gerais. Jales: Embrapa Uva e Vinho, 2005. (Sistema de Produção nº11).

FERREYRA, R.E et al. Efecto del água aplicada em las relaciones hídricas y productividad de lavid 'CrimsonSeedless'. Pesquisa Agropecuária Brasileira, v.41, p.1109-1118, 2006. Disponível em: <http://www.scielo.br/pdf/pab/v41n7/31191.pdf>. Acesso em: 09 de set 2010. Doi 10.1590/S0100-204X2006000700006.

FLORES, C.A et al. Os solos do Vale dos Vinhedos. Brasília, DF: Embrapa, 2012. p.216.

KENNEDY, J. Understanding grape berry development. Practical Winery \& Vineyard Journal, v.2, p.14-23, 2002.

KELLER, M. et al. Ripening grape berries remain hydraulically connected to the shoot. Journal of Experimental Botany, v.57, p. $2577-2587,2006$

KLUTE, A. Water retention: laboratory methods. In: KLUTE, A. (Ed.). Methods of soil analysis: physical and mineralogical methods. 2 ed. Madison: American Society of Agronomy, 1986. p.635-662.

MARINHO, L.B.et al. Produção e qualidade da videira 'Superior Seedless' sob restrição hídrica na fase de maturação. Pesquisa Agropecuária Brasileira, v.44, n.12, p.1682-1691, 2009. Disponível em: <http://www.scielo.br/pdf/pab/v44n12/ v44n12a18.pdf $>$. Acesso em: 21 de fev. 2010. Doi 10.1590/S0100$204 X 2009001200018$.
PADILLA, C. et al. Consumer preference and willingness to pay for an officially certified quality label: implications for traditional food producers. Agricultura Técnica, v.67, n.3, p.300-308, 2007.

R DEVELOPMENT CORE TEAM. R: a language and environment for statistical computing. Vienna, Austria: R Foundation for Statistical Computing, 2011.ISBN $390005107-$ 0. Disponível em: <http://www.R-project.org/>. Acesso em: 10 mar. 2011.

RUFFNER, H.P et al. Soluble and wall associated forms of invertase in Vitis vinífera. Phytochemistry, v.29, 2083-2086, 1990.

RUIZ, H.A.et al. Estimativa da capacidade de campo de latossolos e neossolosquartzarênicos pela determinação do equivalente de umidade. Revista Brasileira de Ciências do Solo, v.27, p.389393, 2003. Disponível em: <http://www.scielo.br/pdf/rbcs/ v27n2/16240.pdf $>$. Acesso em: 2 de fev. 2010. Doi 10.1590/ S0100-06832003000200019.

SOUZA, E.R. et al. Produção de videiras 'Superior Seedless', cultivadas em diferentes tensões de água no solo. Irriga, Botucatu, v.18, n.2, p.232-242, 2013

WILLIAMS, L.E.; TROUT, T.J. Relationship among vineand-soil-based measures of water status in a Thompson Seedless vineyard in response to high-frequency drip irrigation. American Journal. Disponível em: <http://www.ajevonline. org/cgi/issue_pdf/backmatter_pdf/37/4.pdf>. v.56, p.357-366, 2005 